\title{
A legitimidade dos crimes de perigo abstrato em face do princípio da ofensividade ${ }^{1}$
}

Marcelo Carita Correra

Monize Flávia Pompeo

\begin{abstract}
Resumo: O presente estudo, produzido a partir do método lógico-dedutivo com fundamento em revisão bibliográfica de autores nacionais e estrangeiros, busca analisar os crimes de perigo abstrato e sua potencial compatibilidade com a Constituição Brasileira, especialmente diante do princípio da ofensividade (ou lesividade). A sociedade atual, conceituada como uma sociedade de riscos, demanda cada vez mais a manifestação ativa do Estado para regular e evitar atividades potencialmente danosas a bens difusos. Em outras palavras, a sociedade depreca do Estado ações com vistas a disciplinar os riscos decorrentes do convívio social. Inicialmente, o legislador passou a utilizar tipos penais de perigo concreto em conjunto com os tipos penais de dano. Com os riscos cada vez maiores de atividades que podem afetar o meio ambiente ou até mesmo gerar destruição em massa (atividade nuclear), o Estado antecipou ainda mais a tutela penal e criou os crimes de perigo abstrato. Há necessidade de estabelecer um critério objetivo para fixar o limite da legitimidade para criação dos mencionados tipos penais. A proposta testada e confirmada foi reconhecer a constitucionalidade, desde que observem o princípio da precaução. Isto é, a utilização dos referidos tipos só se justifica quando o objeto jurídico protegido for relevante e atrair a incidência do princípio da precaução. Nesse contexto, a antecipação penal promovida é legítima. Isso porque a criação dos tipos de perigo abstrato com fundamento no princípio da precaução entra em conflito com o princípio da ofensividade, que impede a utilização de tipos penais que não impliquem violação de bem jurídico (dano ou perigo concreto). Contudo, diante da relevância de determinados bens, é possível utilizar a técnica de harmonização de princípios, de forma a reduzir o âmbito de atuação do princípio da ofensividade, para que, em determinados casos (como a proteção de bens difusos), exista a incidência conjunta com o princípio da precaução, de forma a permitir a antecipação da tutela penal.
\end{abstract}

Palavras-Chave: Estado. Ofensividade. Precaução. Crime. Perigo Abstrato.

\section{THE LEGITIMITY OF ABSTRACT DANGER CRIMES IN ACCORDANCE WITH THE OFFENSIVE PRINCIPLE}

\begin{abstract}
The present work, produced from the logical-deductive method based on a bibliographic review by national and foreign authors, seeks to study crimes of abstract danger and their potential compatibility with the Brazilian Constitution, especially in view of the principle of offense (or injury). The current society, conceptualized as a risk society, demands more and more active manifestation by the State to regulate and avoid activities potentially harmful to diffuse goods. In other words, to discipline the risks arising from social interaction. The legislator started to use criminal types of concrete danger in addition to criminal types of damage. With the increasing risks of activities that can affect the environment or even generate mass destruction (nuclear activity, for example), the State further anticipated criminal protection and created crimes of abstract danger. There is a need to establish an objective criterion to establish the limit of legitimacy for the creation of crimes of abstract danger. The tested and confirmed proposal was to

\footnotetext{
${ }^{1}$ Marcelo Carita Correra. Graduação em Direito pela PUC/SP. Especialista em Direito Tributário pela PUC/SP. Especialista em Direito Imobiliário pela Escola Paulista de Direito de São Paulo. Especialista em Direito Penal Econômico pela FGV/SP. Mestrando em Direito Penal pela PUC/SP. E-mail: mcorrera@gmail.com.

${ }^{2}$ Monize Flávia Pompeo. Graduação em Direito pela Universidade Estadual Paulista Júlio de Mesquita Filho (2010). Mestranda em Direito Penal pela PUC/SP. E-mail: monizepompeo@gmail.com.
} 
recognize the constitutionality of abstract danger crimes, if they observe the precautionary principle. That is, the use of crimes of abstract danger is only justified when the protected legal object is of great relevance and attracts the incidence of the precautionary principle. In this context, the criminal anticipation promoted by crimes of abstract danger is legitimate. This is because the creation of crimes of abstract danger based on the precautionary principle conflicts with the principle of offensiveness, which prevents the creation of criminal types that do not imply violation of legal property. However, given the relevance of certain legal assets, it is possible to use the principle harmonization technique, in order to reduce the scope of the offensive principles so that, in certain cases (such as the protection of diffuse assets) there is a joint incidence of the precautionary principle, to anticipate the penal incidence for a moment prior to the actual violation of the legal good.

Keywords: State. Offensive. Precaution. Crime. Abstract danger.

\section{INTRODUÇÃO}

A fundação do Estado Liberal, fixada na Revolução Francesa, fato histórico notório de 1789, estabeleceu um novo paradigma das relações interpessoais e, sobretudo, da relação entre cidadão e Estado.

A principal característica do nascimento do Estado Liberal é a necessidade de derrubar os pilares do absolutismo. A existência de uma nobreza e a premissa de que o Estado é isento de responsabilidade cessam com a criação do Estado Liberal.

A instituição da República sintetiza essa importante evolução histórica. O poder passa a ser de titularidade do povo e exercido para o povo e pelo povo. O Estado passa a ser visto como um ente abstrato criado para regulação da vida social. Esse ente abstrato, outrora a personificação do poder do soberano, passa a ser considerado a personificação do poder popular. Nesse diapasão, os poderes estatais passam a ser meramente instrumentais e concedidos de forma precária, vale dizer, somente para realização dos fins comuns aprovados pelo povo e para garantia dos direitos individuais fundamentais.

Os direitos individuais frente ao Estado não são mais vistos como meras liberalidades, mas sim como núcleos duros que constituem verdadeiros limites à atuação estatal. Em outras palavras, o centro de poder foi transferido do Estado para o povo. $O$ anteriormente soberano tornou-se servo da coletividade, tendo como limites objetivos expressos os direitos individuais inalienáveis.

O direito penal torna-se o principal ponto de contato, e ao mesmo tempo de conflito, entre Estado e cidadão. Embora o povo tenha conferido o monopólio da força para o Estado, de forma a viabilizar a vida harmônica, esse dever-poder precisa ser limitado, para impedir que o Estado afete, de forma indevida, os direitos do cidadão e, sobretudo, a liberdade. 
O presente estudo buscou, tomando como tema a limitação do poder estatal em face do cidadão, averiguar a legitimidade do uso dos crimes de perigo abstrato, tipos penais em que se castiga a conduta tipicamente perigosa como tal, sem que tenha ocorrido um resultado de exposição a perigo concreto ou um dano efetivo ao bem jurídico. De forma ainda mais precisa, será analisada a compatibilidade dos referidos tipos penais com a Constituição Federal.

Haverá enfoque sobre o princípio constitucional da ofensividade, de forma a verificar se os crimes de perigo abstrato não seriam, em tese, ilegítimas antecipações da incidência penal.

O estudo é relevante, na medida em que, diante do reconhecimento da existência de uma sociedade de riscos, o direito penal passou a ser utilizado como prima ratio ou até mesmo como sola ratio na regulação de comportamentos relevantes.

O método utilizado será o lógico-dedutivo, com fundamento em revisão bibliográfica dos principais doutrinadores nacionais e estrangeiros que se debruçaram sobre o tema.

Por fim, o estudo pretende jogar luz sobre a necessidade de se estabelecer um critério objetivo e claro para delimitar o campo de legitimidade dos tipos de perigo abstrato, tendo como pano de fundo o potencial conflito entre o princípio constitucional da ofensividade e o princípio constitucional da precaução, o qual proíbe a prática de conduta que, apesar da incerteza científica sobre o nexo causal, tem potencialidade para gerar danos a bens jurídicos relevantes.

Será possível concluir que os crimes de perigo abstrato, a priori, violam o princípio constitucional da ofensividade, que dispõe sobre a legítima intervenção estatal apenas se houver efetivo e concreto ataque a um interesse socialmente relevante - conforme será explorado em capítulo próprio. Contudo, utilizando as técnicas de conciliação de princípios, bem como estabelecendo determinados critérios objetivos no momento de criar o fato típico, os referidos tipos penais podem ser acolhidos no sistema jurídico pátrio como legítimos.

\section{O DIREITO PENAL LIBERAL E A CONSTITUCIONALIZAÇÃO DO DIREITO PENAL}

A Revolução Francesa inaugurou uma nova ordem social. O absolutismo saía de cena e dava espaço à formação do Estado Liberal (TOCQUEVILLE, 2016, p. 45). Nesse momento histórico, a preocupação do legislador era a formação de uma legislação de bloqueio, limitando o poder do Estado (CUNHA JR, 2013, p. 31/32).

Esse novo período histórico implicou a mutação de um Estado absolutista para um Estado Constitucional. Ou seja, a mudança para um ordenamento onde o poder estatal é exercido nos termos da Constituição (BONAVIDES, 2007, p. 29). 
O Estado passa a ser visto não mais como o titular do monopólio do uso da força, mas como o mandatário da vontade geral. O exercício do poder estatal (especialmente o uso da força) deve encontrar seu fundamento na vontade coletiva, na exata necessidade de manutenção da vida harmônica, mas sem abusos (BOBBIO, 2004, p. 135).

É nesse contexto histórico que surge o Direito Penal Liberal, caracterizado como norma de ultima ratio, somente devendo intervir quando outros ramos do direito não forem suficientes para equacionarem o conflito social (ROXIN, 1997, p. 65)

O traço mais relevante do Direito Penal Liberal é que não se pode utilizar o poder punitivo do Estado diante de "quaisquer condutas de potencialidade lesiva ínfima ou conflitos que pudessem ser resolvidos por outras esferas do controle social informal ou formal não-penal” (CARVALHO, 2008, p. 84).

É diante desse quadro que Luiz Flávio Gomes (2003, p. 236) define o Direito Penal Liberal como protetor dos direitos fundamentais da pessoa humana e limitador do poder punitivo. A utilização do direito penal como ultima ratio serve, ao fim e ao cabo, como garantia dos direitos fundamentais e da limitação do poder do Estado, na medida em que o poder punitivo não pode ser utilizado de forma discricionária. Trata-se, portanto, do "guardião das fronteiras da renúncia à liberdade absoluta pactuada no contrato social” (HASSEMER, 2008, p. 35).

Influenciado por esse movimento histórico de limitação do poder estatal, a Constituição pátria adotou princípios expressos para limitação das normas de direito penal, com a aplicação do princípio da proporcionalidade (sanção útil e necessária à finalidade do direito e nada além), subsidiariedade (intervenção do direito penal somente em última instância) e ofensividade (intervenção somente diante de lesão a bem jurídico).

A adoção dos princípios acima expostos no texto magno permitiu estabelecer o conceito de Direito Penal Material. Além dos requisitos formais, somente é possível afirmar a legitimidade do direito penal quando ocorre a efetiva lesão de um bem jurídico protegido ou exposição a perigo concreto (GOMES, 2007, p. 192).

Os princípios acima indicados representam valores que devem orientar não somente a interpretação do texto constitucional, mas também o legislador e os operadores. Isto é, são pilares de sustentação de todo o sistema que vinculam todas as demais normas jurídicas. Celso Antônio Bandeira de Mello (2004, p. 451) afirma que: "o princípio é um mandamento nuclear de um sistema, verdadeiro alicerce dele, disposição fundamental que se irradia sobre diferentes normas".

Robert Alexy (2002, p. 92/93), ao tratar dos princípios, afirma que são normas de otimização do sistema. São normas que ordenam que algo seja realizado. O mesmo autor 
determina um critério relevante para superar o conflito de princípios. Trata-se da redução proporcional, de forma que exista uma harmonização e não a prevalência de uma norma sobre outra. Utiliza, portanto, um critério oposto ao adotado por Ronald Dworkin (2005, passim), que estabelece uma regra de prevalência.

Diante desses ensinamentos sobre o poder vinculante da Constituição Federal sobre o direito penal e, sobretudo, diante da observância dos princípios de direito penal acolhidos no texto magno, o principal critério adotado para limitação do poder punitivo estatal decorre do princípio da ofensividade, na medida em que não se legitima norma penal que não revele conduta que gere efetiva ameaça ou efetiva lesão a bem jurídico.

Paulo César Busato (2018, p. 1073) estabelece critério para determinar o que pode ser considerado como bem jurídico: "somente podem ser objeto de incriminação ataques graves a bens jurídicos essenciais para o desenvolvimento humano em sociedade".

Claus Roxin (1998, p. 27/28) afirma que os bens jurídicos são: "pressupostos imprescindíveis para a existência em comum, que se caracterizam numa série de situações valiosas, como, por exemplo, a vida, a integridade física, a liberdade de atuação, ou a propriedade".

Helena Regina Lobo da Costa (2010, p. 6), por sua vez, afirma que "a Constituição é apenas um limite negativo ao direito penal [...] Isso porque a proteção de um bem jurídico é pressuposto inarredável do tipo penal, mas de forma suficiente".

Logo, os bens jurídicos protegidos pela norma penal devem ser os bens relevantes e com previsão constitucional. Vale dizer, como forma de limitação do poder estatal, não se pode admitir a criação de tipos penais que tutelem bens jurídicos que o Constituinte original não alçou à qualidade de bem jurídico protegido.

\section{A SOCIEDADE DE RISCOS}

O mundo contemporâneo apresenta diversas diferenças em relação à sociedade formada logo após a Revolução Francesa. A necessidade de estabelecer normas e conceitos jurídicos capazes de limitar o poder estatal em face do cidadão, apesar de ser uma preocupação constante, perde seu posto de protagonista em face das novas demandas que o Estado precisa responder (FARIA, 2007, passim).

Diante da expansão tecnológica, o ser humano passou a deter conhecimentos capazes de afetar a natureza de forma irreversível. Os notórios casos de Mariana e Brumadinho, apenas para citar alguns, revelam o potencial danoso das intervenções humanas. 
Essa sociedade gerou o que Ulrich Beck (2010, p. 24) passou a chamar de sociedade de riscos: "O novo paradigma da sociedade de risco se apoia fundamentalmente na solução de um problema similar e no entanto inteiramente distinto. Como é possível que as ameaças e riscos sistematicamente coproduzidos no processo tardio de modernização sejam evitados". No mesmo sentido é a opinião de Celso Fernandes Campilongo (2012, p. 35).

A sociedade de riscos foi retratada no direito por meio do princípio da precaução, definido como o mandado de otimização para evitar o risco de atividade ou comportamento que, segundo a ciência, revela-se situação de potencial lesão a bens jurídicos relevantes (LEITE, 2003, p. 226).

A sociedade contemporânea, portanto, é caracterizada pelos riscos e a consequente demanda social para que o Estado regule as condutas que geram riscos. É nesse contexto que o direito penal, fundamentado na precaução, se expande. O legislador passa a acreditar que a punição de meras condutas e a antecipação da sanção penal para atos preparatórios são elementos eficazes para criar uma cultura de prevenção.

É nesse cenário que o direito penal liberal começa a ceder e se modificar. A legislação de bloqueio, subsidiária e destinada a garantir liberdades negativas, não é mais suficiente para corresponder aos anseios da sociedade de risco. O paradigma da incidência penal diante da ocorrência do dano ao bem jurídico já não se mostra útil. É preciso antecipar a atividade penal, punir meras condutas e atos preparatórios antes que o dano ao bem jurídico tenha início. É nesse contexto que há migração do Direito Penal Liberal para o Direito Penal Moderno.

3.1 O direito penal na sociedade de riscos

Confrontado pelas demandas sociais para evitar ou minimizar os riscos, o Estado amplia sua interferência sobre a sociedade e rompe as antigas barreiras que, nos primórdios do liberalismo, delimitavam a esfera pública e privada. O Estado passa a intervir diretamente nas atividades produtoras de risco.

Dentre os mecanismos à disposição do Estado para regular o risco, está o direito penal que, sobretudo na esfera ambiental e na esfera econômica, é utilizado como prima ratio e não como ultima ratio.

Claus Roxin (1997, p. 65/66) afirma a impossibilidade de utilização da norma penal como prima ratio. Direito penal é, para o citado autor, norma de aplicação subsidiária. Não deve ser utilizada como prima ratio. Na verdade, o Direito Penal Liberal, em suas premissas, se aproxima do direito penal mínimo (SÁNCHEZ, 1992, p. 38). 
Haveria legitimidade em utilizar o direito penal como primeira linha de defesa da sociedade em determinados temas? Como regra geral, o direito penal não pode ser acionado como prima ratio.

Contudo, há situações em que o Estado não só pode, mas deve, utilizar força máxima para regular determinado comportamento, sendo o direito penal a prima ratio por essência (MARTÍN, 2005, p. 46-47).

É nesse momento que o direito penal passa da fase liberal para a fase moderna. A demanda pela proteção preventiva de bens jurídicos não pode ser satisfeita com as velhas premissas do Direito Penal Liberal. Há necessidade de uma nova dogmática.

É preciso expandir o direito penal, na medida em que há: aparição de novos interesses como bens jurídicos merecedores de proteção; efetiva aparição de novos riscos decorrentes de avanços técnicos (ciberdelinquência); e eliminação de espaços de risco permitido e incremento de infrações de deveres de cuidados (SÁNCHEZ, 2001, p. 25-79).

Salo de Carvalho (2008, p. 88) sintetiza com precisão as modificações da sociedade que impuseram a transição do Direito Penal Liberal para o Direito Penal Moderno, ao afirmar que "se o controle no século XIX ocorria post factum, mediante indenização, no século XX a ideia de resguardo técnico dos riscos impõe modelo de antecipação do dano via medidas preventivas".

Nesse contexto, as premissas do Direito Penal Liberal precisam ceder frente às novas necessidades da sociedade. O princípio da ofensividade precisa ser mitigado em prol do princípio da precaução, de forma que o direito penal possa intervir na sociedade para evitar a lesão a bens jurídicos e não apenas para punir condutas que já tenham lesado o bem juridicamente protegido. Isto é, a legislação deve antecipar a incidência da sanção penal para os atos anteriores ao dano efetivo e para punir condutas, antes não tipificadas, mas que descumprem deveres essenciais, de forma a bloquear atitudes que podem lesar bens jurídicos relevantes.

3.2 O princípio da precaução na dogmática penal

O princípio da precaução foi previsto no programa do governo alemão de proteção ambiental de 1971 e foi incorporado de modo explícito - como na Lei de Proteção contra a contaminação de 1974 (art. $1^{\circ}$ ), na Lei sobre o uso de energia atômica de 1985 (art. $7^{\circ}$, II) e na Lei sobre produtos químicos de 1980 (art. $1^{\circ}$ ) - ou implícito - como na Lei de técnicas genéticas de $1990\left(\right.$ art. $1^{\circ}$ ) e na Lei de proteção das águas de 1996 (art. $4^{\circ}$ ) - em diversas leis ambientais alemãs (ANDORNO, 2004, p. 20/26). 
A Constituição Federal pátria reconheceu expressamente o princípio da precaução artigo $225, \$ 1^{\circ}$, IV. Trata-se de norma fundamental "ditando a cautela jurídica que deve reger as atividades enquadradas num quadro de incerteza científica quanto a possíveis danos e riscos que possam causar ao ambiente, mesmo que potenciais" (SARLET; FENSTERSEIFER, 2011, p. 237).

O princípio da precaução, portanto, é norma constitucional que, diante de incerteza científica sobre determinada atividade e sobre o nexo causal em relação ao resultado danoso, impõe a cautela, mediante a adoção de conduta que anule o risco de dano.

Uma primeira abordagem dogmática para o princípio em questão é a construção da noção de periculosidade da conduta. Ou seja, a antecipação da sanção penal para condutas de descumprimento de deveres ou atos preparatórios. Essa tendência tem justificativa no enfoque preventivo que o Direito Penal contemporâneo adota, orientado à limitação do risco e à busca incessante por segurança jurídica (SÁNCHEZ, 2001, p. 25-79).

Cabe destacar que uma dificuldade presente na utilização do princípio da precaução na esfera penal decorre da inexistência de certeza científica sobre o nexo causal das condutas. Quando há incidência do princípio da precaução, há presença de dúvida objetiva sobre os danos que determinadas atividades podem gerar para bens jurídicos relevantes. Assim, a primeira barreira que a dogmática penal precisa enfrentar é determinar a legitimidade de tipos penais sem a perfeita ciência do nexo causal das condutas.

É nesse momento que os crimes em questão se tornam relevantes no cenário do direito penal. Com fundamento no princípio da precaução, o legislador passa a utilizar a norma penal como forma de antecipar a tutela e evitar danos irreparáveis. Expande a tutela penal na expectativa de que a antecipação da sanção seja capaz de evitar danos.

Contudo, esse procedimento somente pode ser tido como legítimo se houver o mínimo de fundamento científico que comprove um potencial nexo de causalidade entre a conduta tipificada e o possível dano ao bem jurídico tutelado.

Note-se que, por se tratar de crime de perigo abstrato, não se exige a configuração de resultado naturalístico ou risco concreto de dano. Contudo, para que exista legitimidade penal, é preciso demonstrar que a conduta eleita como fato típico é potencialmente lesiva ao bem jurídico. Ou seja, que a conduta tem potencial para, com um mínimo de evidência científica, gerar nexo causal capaz de afetar o bem jurídico protegido.

É precisamente nesse ponto que o princípio da precaução e da ofensividade em matéria penal apresentam ponto de contato e levam a teste a legitimidade os tipos de perigo abstrato. Conforme será explorado em capítulo seguinte, é preciso solucionar o conflito entre os dois 
princípios acima indicados, de forma a estabelecer um critério objetivo para delimitar a fronteira entre a legitimidade e o abuso.

Trata-se do confronto entre direito penal da ofensividade e direito penal da periculosidade, conforme Antonio Gacía-Pablos de Molina e Luiz Flávio Gomes (2012, p. 375).

\subsection{O Princípio da Ofensividade}

O princípio constitucional da ofensividade pode ser definido como a limitação do poder punitivo do Estado em face do cidadão, na medida em que o legislador somente pode eleger como típicas condutas que lesem bens jurídicos tutelados pelo direito penal.

Cezar Roberto Bitencourt (2008, p. 22) afirma que "somente se justifica a intervenção estatal em termos de repressão penal se houver efetivo e concreto ataque a um interesse socialmente relevante, que represente no mínimo, perigo concreto ao bem jurídico tutelado”.

A razão do princípio é simples. Se o Estado tivesse a possibilidade de criar tipos penais contemplando condutas incapazes de lesionar o bem jurídico, a liberdade do cidadão estaria severamente ameaçada (GOMES, 2002, p. 15).

O princípio da ofensividade possui função político-criminal, operando como limite material para criação legislativa de tipos penais, e também detém função interpretativa ou dogmática - no momento da interpretação da norma penal, impedindo a incidência de tipo penal quando se verifica somente o requisito formal, mas não material da conduta (BITENCOURT, 2008, p. 22).

É possível concluir, portanto, que o princípio da ofensividade é um dos dogmas do direito penal clássico, cuja principal função era garantir a harmonia social sem determinar a demasiada redução dos direitos individuais e sem dotar o Estado de poderes ilimitados.

A primeira função do princípio da ofensividade é impedir a criação e a incidência da norma penal quando não ocorrer dano ou perigo concreto de dano a determinado bem jurídico. Para a legitimidade do tipo penal, não basta a correlação abstrata entre a conduta tipificada e o bem jurídico protegido. É preciso que a conduta gere, efetivamente, dano ou perigo concreto de dano. Esse foi o mecanismo acolhido pelo direito penal clássico para limitação do poder estatal.

\section{OS CRIMES DE PERIGO ABSTRATO}

Consoante a evolução da sociedade exposta nos itens supra e diante da legitimidade da utilização do direito penal como prima ratio em casos específicos, o Estado passou a utilizar os 
crimes de perigo abstrato como principal técnica para regular comportamentos capazes de gerar riscos.

São tipos penais que não exigem resultado naturalístico para sua consumação, vale dizer, não demandam lesão efetiva ou mesmo perigo concreto ao bem jurídico. A mera conduta praticada pelo agente já é suficiente para a incidência do tipo penal.

Claus Roxin (1997, p. 407) conceitua tipos de perigo abstrato como "aqueles em que se castiga a conduta tipicamente perigosa como tal, sem que no caso concreto tenha que ocorrer um resultado de exposição a perigo".

Trata-se, portanto, de tipo penal em que há a determinação da conduta proibida e a imputação independente de qualquer comprovação efetiva de dano ao bem jurídico protegido, seja um dano efetivo ou perigo concreto.

É nesse ponto que surge a principal questão sobre os crimes de perigo abstrato. É possível fundamentar sua legitimidade no princípio da precaução. Por outro lado, essa interpretação testa os limites do Direito Penal Liberal, cuja premissa é a utilização do direito penal mínimo, sobretudo como forma de garantia de liberdades.

O desafio que os referidos crimes nos oferecem é a fronteira entre um direito penal mínimo, de base liberal e fundado no princípio da ofensividade, e um direito penal maximizador (ou moderno), onde o campo de atuação é expandido na busca de não somente punir condutas lesivas, mas antecipar a sanção para condutas potencialmente lesivas. É esse ponto de contato entre princípio da ofensividade e precaução que precisa ser endereçado.

4.1 A problemática da legitimidade dos crimes de perigo abstrato

É preciso verificar, nesse ponto do estudo, quais as possíveis alegações de inconstitucionalidade que podem afetar os crimes de perigo abstrato. Primeiramente, cabe destacar que é possível analisar a relação da conduta tipificada com o bem jurídico protegido.

Um exemplo pode aclarar o aqui exposto. O crime de porte de arma de fogo (artigo $14 \mathrm{da}$ Lei $10.826 / 2003$ ) é um típico crime de perigo abstrato. $O$ mero porte, não autorizado pela autoridade competente, de arma de fogo municiada não causa dano a nenhum bem jurídico protegido e nem mesmo expõe a perigo concreto.

O que se incrimina no tipo penal em questão é a simples conduta de portar arma sem autorização. Não há espaço, nesse tipo penal, para questionamento sobre perigo real ou dano. Nesse contexto, é plenamente viável determinar qual o bem jurídico protegido pelo legislador. A conduta incriminada tem como função a proteção da vida humana (bem jurídico primordialmente 
tutelado pelo texto magno). Busca-se evitar conduta que, potencialmente, pode causar danos à vida humana. Pretende-se impedir o porte não autorizado de arma de fogo para reduzir ou mesmo anular o risco de lesão à vida humana.

É preciso destacar que há entendimento no sentido que o bem jurídico protegido pelo delito de porte de arma de fogo é a incolumidade pública (CAPEZ, 2014, p. 361). Ou seja, o que a norma penal buscaria proteger é a paz e a tranquilidade do convívio social, que seriam afetadas na hipótese de pessoas portarem armas de fogo sem a devida autorização. Esse entendimento já foi acolhido em julgado do Superior Tribunal de Justiça ${ }^{2}$.

Apesar da lição acima citada, mantemos o entendimento de que o bem jurídico protegido no crime de porte de arma de fogo é a vida humana. Isso porque entendemos que não se pode afirmar que a incolumidade pública é um bem jurídico.

De fato, não se pode tutelar conceitos vagos e sem definição precisa como bens jurídicos. Afinal, como delimitar, com precisão, o que seja incolumidade pública? O fato é que conceitos vagos e indeterminados, como a incolumidade pública, não são bens jurídicos penalmente tutelados, sob pena de violação do princípio da taxatividade e da ofensividade. Não se pode deixar, pela via da utilização de conceitos vagos, que o Estado crie tipos penais que não permitam controle material da legitimidade. A mesma situação se repete com os supostos crimes contra a saúde pública. O que é saúde pública para fins de determinação de bens jurídicos protegidos? É impossível obter qualquer definição com a precisão necessária à observância do princípio da taxatividade.

Durante o domínio Nazista na Alemanha (1933-1945) houve a utilização de conceitos abstratos e vagos como bens jurídicos (sentimento do povo alemão, por exemplo), o que permitia que o Estado estipulasse tipos penais sem a devida limitação (ZAFFARONI, 2019, passim).

Não se pode acolher a incolumidade pública como um bem jurídico, mesmo afirmando que se trata de bem difuso e que, portanto, teria inegável conteúdo vago. Não se pode confundir bem jurídico difuso com bem jurídico vago (não acolhido em matéria penal). Bem jurídico difuso é, por exemplo, o meio ambiente ecologicamente equilibrado. Nesse caso é possível vislumbrar os limites do conteúdo do bem jurídico protegido (a preservação da biosfera para garantia da vida humana). Assim, nesse caso, é possível estabelecer um critério objetivo com base no bem jurídico difuso (meio ambiente) para legitimar a criação de tipos penais. Situação diversa se dá no caso da incolumidade pública, cuja redação vaga e aberta não permite essa delimitação.

Verifica-se, portanto, que inexiste qualquer impossibilidade de determinação do bem jurídico protegido nos tipos de perigo abstrato. O ponto de possível questionamento dos tipos

\footnotetext{
${ }^{2}$ Nesse sentido: BRASIL. STJ. HC 307.574 - SP. Relator: Ministro Felix Fischer. Brasília, DF, 24 de março de 2015.
} Disponível em: <http://www.stj.gov.br>. Acesso em: 16 abr. de 2020. 
penais em estudo é: apesar de identificado o bem jurídico protegido, há possibilidade de aplicar sanção penal quando nem mesmo perigo concreto é verificado? É legítima a antecipação da tutela penal a ponto de determinar a incidência da norma por uma simples conduta que não chega nem mesmo a expor o bem jurídico a perigo concreto?

$\mathrm{Na}$ verdade, a problemática apontada pode ser sintetizada da seguinte forma: apesar dos crimes de perigo abstrato serem compatíveis com a teoria do bem jurídico, a antecipação da tutela penal para o momento do mero descumprimento de um dever ou para os atos preparatórios encontra óbice no princípio da ofensividade? O princípio da precaução seria capaz de, por si só, sustentar a legitimidade dos referidos tipos penais?

\subsection{O Princípio da Precaução em face do Princípio da Ofensividade}

Verificado o conflito entre princípios jurídicos (ofensividade e precaução) gerado pela criação de crimes de perigo abstrato, é necessário verificar qual o critério a ser estipulado para determinar a legitimidade desse tipo penal.

Por exemplo, a potencialidade lesiva do material radioativo demanda que o Estado, obedecendo ao princípio da precaução, antecipe a tutela penal para evitar qualquer conduta potencialmente lesiva ao bem (ainda que não seja constatado perigo concreto).

Essa argumentação é utilizada pelos defensores dos tipos penais em questão para afirmar a legitimidade dessa técnica legislativa. Isto é, na situação de dano potencial a bens jurídicos relevantes, deveria prevalecer o princípio da precaução e não o da ofensividade; ou, ao menos, que o princípio da ofensividade fosse parcialmente reduzido para permitir a proteção preventiva do bem jurídico.

Ocorre que, ao contrário do afirmado, os tipos de perigo abstrato não resistem ao teste de constitucionalidade quando confrontados com o princípio da ofensividade. A opinião aqui exposta parece ser suportada por José Francisco de Faria Costa (2000, p. 624) quando afirma: “de fora fica, em verdadeiro rigor, todo o reino de legitimidade da punição de condutas cujo traço essencial não está no fato de o perigo se ter concretamente desencadeado, mas sim e diferentemente em o perigo ser considerado como mera motivação para o legislador punir tal conduta".

No mesmo sentido, Luiz Flávio Gomes (2002, p. 89) ressalta a necessidade de condutas concretamente ofensivas ao bem jurídico para fins de incidência penal. Pondera, o autor, que se trata de exigência de um regime de direito penal democrático. 
Tomando os ensinamentos acima expostos, seria determinante declarar a inconstitucionalidade de todos os tipos penais em questão; afinal, não haveria fundamento para criar tipos penais com base em mera conduta. Neste sentido, Bitencourt (2013, p. 61) afirma que "para que se tipifique algum crime, em sentido material, é indispensável que haja, pelo menos, um perigo concreto, real e efetivo de dano a um bem jurídico penalmente protegido. Somente se justifica a intervenção estatal em termos de repressão penal se houver efetivo e concreto ataque a um interesse socialmente relevante".

Há, portanto, entendimento que estabelece a inconstitucionalidade dos crimes de perigo abstrato com fundamento no princípio da ofensividade. Não haveria fundamento constitucional para afastar o mencionado princípio como requisito mínimo da incidência do direito penal. Como se trata de um princípio voltado à preservação dos direitos individuais, não haveria fundamento para seu afastamento ou redução do âmbito de incidência.

Contudo, pensamos que esse não é o melhor entendimento. Para a legitimidade dos tipos penais em questão, há a necessidade de redução proporcional de um direito fundamental (princípio da ofensividade), de forma a permitir a compatibilização com o princípio da precaução. Trata-se da aplicação da teoria estabelecida por Robert Alexy (2015, p. 93/94) para determinar a solução jurídica em casos de conflitos de princípios.

Note-se que não se trata de afastar o princípio da ofensividade, mas somente reduzir seu âmbito de atuação, para permitir que o princípio da precaução, que também tem base constitucional, seja observado. Ou seja, trata-se de uma ponderação de princípios.

Há, portanto, redução proporcional dos princípios em conflito que incidem no tipo penal, de forma a harmonizar a interpretação do direito. No exemplo acima, o princípio da ofensividade cede parcialmente em favor do princípio da precaução, de forma a compatibilizá-los.

Conforme já mencionado, seria possível, em tese, afirmar que o princípio da ofensividade, por ser um direito fundamental concedido ao cidadão como forma de obstar a ilegítima invasão da liberdade pelo Estado, não admitiria qualquer forma de redução. Logo, não haveria que se falar em harmonização ou sopesamento de princípios, mas da prevalência do princípio da ofensividade.

Entendemos que essa afirmação não reflete o melhor direito, na medida em que parte da premissa da existência de direitos absolutos, que não podem ser reduzidos em nenhuma situação. Ocorre que os direitos fundamentais admitem redução para sopesamento com outros princípios de mesma hierarquia. 
Virgílio Afonso da Silva (2014, p. 197) afirma que "restrições a direitos fundamentais que passam no teste da proporcionalidade não afetam o conteúdo essencial dos direitos restringidos.” No mesmo sentido é a opinião de Friedrich Müller (1969, p. 41).

O próprio Robert Alexy (2015, p. 110) traz arrazoado aclarando a impossibilidade de existência de princípios absolutos e ilimitados, mesmo quando garantem direitos individuais fundamentais.

Portanto, a constitucionalidade dos tipos de perigo abstrato em face do princípio da ofensividade deve ser analisada em cada tipo penal, tendo como pano de fundo o princípio da precaução. Quando o tipo penal de perigo abstrato não protege bem jurídico que demanda observância do princípio da precaução, o tipo é ilegítimo. De outro lado, se o tipo buscar proteger bem jurídico sujeito à incidência do princípio da precaução (meio ambiente, por exemplo), é de rigor reconhecer a constitucionalidade.

O princípio da precaução é, dessa forma, em cada tipo penal, o critério a ser utilizado para testar e certificar a constitucionalidade. É a fronteira entre a legitimidade e ilegitimidade dessa técnica legislativa característica da sociedade de riscos. Isso tudo se dá pela necessidade de adaptar o direito às demandas sociais, mas sem ignorar as conquistas fundamentais do liberalismo, que fixaram as bases para limitação do poder estatal em face do cidadão por meio do princípio da ofensividade.

\section{CONCLUSÃO}

O presente estudo teve como ponto de partida a criação de uma sociedade de riscos e a demanda do meio social para que os referidos riscos fossem regulados e minimizados pelo Estado que, respondendo à sociedade, passou a utilizar os crimes de perigo abstrato para obstar condutas potencialmente lesivas a bens jurídicos relevantes. Isto é, a aplicação da tutela penal mesmo diante da inexistência de dano ou perigo concreto foi utilizada como forma de controle de riscos.

A pesquisa realizada baseou-se em revisão bibliográfica de doutrinadores nacionais e estrangeiros, por meio do método lógico-dedutivo.

A primeira parte do trabalho foi dedicada à sociedade de riscos e às mudanças na legislação penal decorrentes dessa nova realidade social que, rompendo os limites impostos pelo Estado Liberal, demandou posição ativa do Estado na proteção de bens difusos e, sobretudo, na redução de riscos. 
Ainda na primeira parte do trabalho, verificou-se que o Estado optou pelo direito penal como prima ratio, ou até mesmo como sola ratio, na proteção de bens difusos relevantes (meio ambiente, por exemplo). Esse fenômeno de expansão do direito penal foi caracterizado, inicialmente, pela utilização dos crimes de perigo concreto e, posteriormente, dos crimes de perigo abstrato.

A segunda parte do trabalho foi dedicada aos crimes de perigo abstrato. Após a definição do conceito dos citados tipos penais, foi possível verificar que há verdadeira pressão sobre os limites estabelecidos pelo Estado Liberal para regular o poder punitivo. Em outras palavras, os tipos penais de perigo abstrato passaram a desafiar as balizas fixadas pelo liberalismo que, para garantia da liberdade do cidadão, impedem a criação de tipos penais diante de fatos que não revelem lesão a bem jurídico.

A principal contraposição aos crimes de perigo abstrato se deu diante do princípio constitucional da lesividade que, em observância aos paradigmas liberais e ao direito penal mínimo, impede o exercício da norma penal quando não verificada a efetiva violação do bem jurídico.

Afinal, se confrontarmos os tipos penais de perigo abstrato com o princípio da ofensividade (ou lesividade) haverá necessidade de declarar a inconstitucionalidade dessa técnica legislativa, na medida em que os referidos tipos foram construídos para permitir a incidência da sanção independentemente de qualquer demonstração de dano ou perigo concreto.

Ocorre que a declaração ampla de inconstitucionalidade dos tipos penais de perigo abstrato não é a melhor solução. Referidos tipos precisam ser compatibilizados com as premissas do sistema constitucional pátrio. Dessa forma, os referidos tipos são legítimos quando contemplam atitudes potencialmente causadoras de danos a bem jurídico sujeito ao princípio da precaução. Vale dizer, trata-se de bem jurídico que demanda atuação prévia do Estado, de forma a evitar qualquer violação ou degradação. O exemplo típico é o meio ambiente que, depois de degradado, pode demorar muito tempo até se recuperar, ou até mesmo apresentar irreversibilidade.

Portanto, os tipos penais em estudo são legítimos se o bem jurídico tutelado for relevante ao ponto de atrair o princípio da precaução. O conflito entre princípio da precaução e princípio da ofensividade deve ser resolvido pela aplicação da teoria de Robert Alexy (2015, passim), que determina uma redução proporcional do princípio limitador (no caso, o princípio da ofensividade) para permitir a incidência do princípio específico (precaução).

Julgamos que o presente estudo permitiu revelar um critério objetivo e seguro para analisar a legitimidade dos crimes de perigo abstrato. 
Cabe destacar que uma dificuldade apresentada durante a pesquisa foi a revelação da impossibilidade de localização de estudos profundos sobre o confronto entre princípio da ofensividade e precaução, o que impôs o desenvolvimento de argumentação própria para equacionar a questão nos moldes da proposta aqui formulada.

Por fim, resta fortemente demonstrado que a antecipação da tutela penal é um instrumento legítimo do Estado para fazer frente às demandas decorrentes de uma sociedade de risco; contudo, essa nova realidade normativa não pode se dar sem limites claros e objetivos.

\section{REFERÊNCIAS}

AYALA, Patrick de Araújo; LEITE, José Rubens Morato. Novas tendências e possibilidades do Direito Ambiental no Brasil. In. WOLKMER, Antônio Carlos; LEITE, José Rubens (Org.). Os “novos" direitos no Brasil: natureza e perspectivas: uma visão básica das novas conflituosidades. São Paulo: Saraiva, 2003.

ANDORNO, Roberto. Validez del principio de precaución como instrumento jurídico para la prevención y la gestión de riesgos. In: ROMEO CASABONA, Carlos María (Ed.). Principio de precaución, Biotecnología y Derecho. Bilbao-Granada: Cátedra Interuniversitaria de Derecho y Genoma Humano/Fundación BBVA/ Diputación Foral de Bizkaia/Universidad del País Vasco/Comares, 2004, p.20-26.

ALEXY, Robert. Teoria dos Direitos Fundamentais. 2 ed. Tradução de Virgílio Afonso da Silva. São Paulo: Editora Malheiros, 2015.

Teoría de los Derechos Fundamentales. Madrid: Centro de Estúdios Políticos y Constitucionales, 2002

BECK, Ulrich. Sociedade de Risco - Rumo a uma outra modernidade. Trad. Sebastião Nascimento. 1 ed. São Paulo: Editora 34, 2010.

BITENCOURT, Cezar Roberto. Tratado de Direito Penal - Parte Geral I. 19 ed. Editora Saraiva. São Paulo, 2013.

2008.

.. Manual de Direito Penal. vol. 1. 10 ed. São Paulo: Saraiva,

BOBBIO, Norberto. A Era dos Direitos. Trad. Carlos Nelson Coutinho. Rio de Janeiro: Elsevier, 2004.

BONAVIDES, Paulo. Do Estado Liberal ao Estado Social. $8^{a}$ ed. São Paulo: Malheiros, 2007. BRASIL. Lei 10.826, 22 de dezembro de 2003. Dispõe sobre registro, posse e comercialização de armas de fogo e munição, sobre o Sistema Nacional de Armas - Sinarm, define crimes e dá outras providências. Disponível em: < http://www.planalto.gov.br/ccivil_03/Leis/2003/L10.826compilado.htm>. Acesso em: 19 out. 2019.

BRASIL. STJ. HC 307.574 - SP. Relator: Ministro Felix Fischer. Brasília, DF, 24 de março de 2015. Disponível em: <http://www.stj.gov.br>. Acesso em: 16 abr. de 2020. 
BUSATO, Paulo César. Direito Penal. Parte Geral. 4 ed. São Paulo: Editora Atlas, 2018

CAMPILONGO, Celso Fernandes. Interpretação do Direito e Movimentos Sociais. 1 ed. São Paulo: Elsevier, 2012.

CAPEZ, Fernando. Curso de direito penal. Legislação Penal Especial. v. 4. 18. ed. São Paulo: Saraiva, 2014. p. 361.

CARVALHO, Salo de. Anti-manual de Criminologia. $2^{\mathrm{a}}$ ed. - Rio de Janeiro: Lumen Juris, 2008.

COSTA, Helena Regina Lobo da. Proteção Penal Ambiental: viabilidade - efetividade-tutela por outros ramos do direito. 1 ed. São Paulo: Saraiva, 2010.

COSTA, José Francisco de Faria. O Perigo em Direito Penal. 1 ed. Coimbra: Coimbra Editora, 2000 .

CUNHA JR., Dirley da. Curso de Direito Constitucional. $7^{a}$ ed. Salvador: Jus Podivm, 2013.

DWORKIN, Ronald. Taking Rights Seriously. England: Motilal Books UK, 2005.

FARIA, Carlos Aurélio Pimenta de. Uma genealogia das teorias e tipologias do Estado de BemEstar Social. In DELGADO, Mauricio Godinho; PORTO, Lorena Vasconcelos. O Estado de Bem-Estar Social no Século XXI. São Paulo: LTr, 2007.

GOMES, Luiz Flávio. Princípio da Ofensividade no Direito Penal. Série as ciências criminais no século XXI. vol. 6. São Paulo: Editora Revista dos Tribunais, 2002.

Direito Penal Tradicional Versus "Moderno e Atual” Direito Penal.

Revista brasileira de ciências criminais. São Paulo, a. 11, n. 42, jan./mar. 2003.

Coordenador. GOMES, Luiz Flávio; MOLINA, Antonio García-

Pablos de. Direito Penal. v. 2. Parte Geral. São Paulo: RT, 2007. p. 192.

., MOLINA, Antonio García-Pablos de. Direito Penal:

fundamentos e limites do Direito Penal. São Paulo: Editora Revista dos Tribunais, 2012.

HASSEMER, Winfried. Direito Penal: fundamentos, estrutura, política. Trad. Adriana Beckman Meirelles [et al.]. Porto Alegre: Sergio Antônio Fabris Ed., 2008.

MARTÍN, Luis Gracia. Prolegômenos para a luta pela modernização e expansão do Direito Penal e para a crítica do discurso de resistência. Trad. Érica Mendes de Carvalho. Porto Alegre: Sergio Antônio Fabris Ed., 2005, p. 46-47.

MELLO, Celso Antônio Bandeira de. Curso de direito administrativo. 17 ed. São Paulo: Malheiros, 2004.

MÜLLER, Friedrich. Die Positivitat der Grundrechte. Fragen einer praktischen Grundrechtsdogmatik. 1 ed. Berlin: Duncker \& Humblot, 1969. 
ROXIN, Claus. Derecho penal: parte general - tomo I. Fundamentos: las estructuras de la teoria del delito. 1 ed. Trad. Diego-Manuel Luzón Peña et all. Madrid: Civitas, 1997.

Problemas fundamentais de direito penal. $3^{\text {a }}$ ed. Lisboa: Vegas, 1998. p.

$27-28$

SÁNCHEZ, Jesús María Silva. Aproximación al Derecho penal contemporâneo. Barcelona: J. M. Bosch Editor S.A., 1992.

La expansión del Derecho Penal: aspectos de la política criminal em las sociedades postindustriales. $2^{\mathrm{a}}$ ed., Madrid: Civitas, 2001.

SARLET, Ingo Wolfgang; FENSTERSEIFER, Tiago. Direito Constitucional Ambiental.

Estudos sobre a Constituição, os Direitos Fundamentais e a Proteção do Ambiente. São Paulo: RT, 2011.

SILVA, Virgílio Afonso da. Direitos Fundamentais: conteúdo essencial, restrições e eficácia. 2 ed. São Paulo: Malheiros, 2014.

TOCQUEVILLE, Alexis de. O Antigo Regime e a Revolução. 2 ed. Tradução: Rosemary Costhek Abílio. São Paulo: Martins Fontes, 2016.

ZAFFARONI, Raul Eugênio. Doutrina Penal Nazista: A Dogmática Penal Alemã entre 1933 a 1945. 1 ed. Trad. Rodrigo Murad do Prado. São Paulo: Tirant lo Blanch, 2019. 